\title{
Effect of salinity stress on the seedlings of Vigna radiata (L.) , Wilczek
}

\author{
${ }^{1}$ Souranshu Jena and Goutam Sabat \\ ${ }^{1}$ P.G. Department of Botany \& Biotechnology, \\ Khallikote Autonomous College, \\ Berhampur-760001, ODISHA, INDIA
}

\begin{abstract}
The present laboratory study was conducted to observe the salinity stress on the seedlings of vigna radiata (mung) of the germination, morphology and some biochemical parameters. The selected concentrations of salt treatment were ranging from $0.128 \mathrm{~g}$ to $0.896 \mathrm{~g}$ or $1 \mathrm{dS} / \mathrm{m}$ to $6 \mathrm{dS} / \mathrm{m}$. The control seeds were grown in distilled water for the purpose of comparisons. In germination parameters , \% of germination of seeds and emergence of leaf decreased with the increase in salt stress. The Shoot and Root length, R/S ratio and fresh weight and dry weight of the seedlings also declined significantly in comparison to control seedlings. The changes in pigment content under salinity stress did not show any regular response and there was insignificant changes in pigment content. The biochemical parameters like Amino acids and sugar in shoot and root of the seedlings declined with salt stress whereas protein and Nucleic acids (DNA and RNA) content did not respond in comparison to control values.
\end{abstract}

Keywords: Salinity, Mung, Seedlings, Biochemistry, V Germination

\section{Introduction}

Salinity is one of the major factors that affect plant growth and metabolism, leading to severe damage and a loss of productivity mainly in arid and semi arid regions (Vaidyanathan et al., 2003).Salinity is a generic term used to describe the elevated concentration of soluble salts in the soil and water. Out of the soluble salts present in soil and water Sodium chlorides $(\mathrm{NaCl})$ are highly soluble than others, thus it has major impact on salinity stress.

Exposure of plants to salinity results in increased generation of reactive oxygen species (ROS)such as singlet oxygen,hydrogen peroxide, hydroxide radicals, superoxide, etc as by-products, which damage the cellular components (Van Breusegem and Dat, 2006) and vital macromolecules of plant such as protein, lipid, carbohydrates, DNA, RNA, etc by causing oxidative damage (Apel and Hirt, 2004 ; Ahmad,2010).Reactive oxygen species cause chlorophyll degradation and membrane lipid peroxidation, reducing membrane fluidity and selectivity (Verma and Mishra, 2005).Mung bean is an important, self-pollinate, environment friendly, proteins, minerals and vitamins, it is and indispensable ingredient in majority of Indian. of mung beans. In response to salt stress, crop varieties/genotypes vary in their inherent ability to adjust several physiological and biochemical processes ( Grewal, 2010; Singh et al., 2014). Saha (2010) along with his coworkers stated that with the increase in the salt concentration, seed germination, fresh and dry weight, root and shoot length, photosynthesis, yield parameters affected and reduced drastically.. Extremely high salt stress conditions damage the plant, but moderate to low salt stress affects plant growth rate and thereby manifests symptoms that could be associated with morphological, physiological, or biochemical change (Hasegawa, 2013).

\section{Materials and Methods}

Mung bean (Vigna radiata L.; Family: Fabaceae) is well known as green gram or mung bean. Mung bean has been consumed as a common traditional food worldwide for more than 3500 years.

Vigna radiata used to be known as Phaseolus aureus Roxb Mung bean (Vigna radiata L.) is an economically important food legume rich in nutrients.

Native variety of Vigna radiata (L.) Wilczek was used as the experimental plant seed were obtained from the Centre for Pulses Research Institute, Ratanpur, Berhampur (CPRI) with label IPM-02-14.The selected species is popularly known as Green gram or Mung. The seeds were sterilized with distilled water. Then the seeds were soaked for 24 hours and then spread over the nutrient solution by the help of hydroponic culture technique. Sodium Chloride $(\mathrm{Na} \mathrm{Cl})$ was used as test chemicals with molecular weight $58.41 \mathrm{gm} / \mathrm{mole}$. Different concentrations of salt solution were prepared by using Hoagland solution as the solvent. The Hoagland solution is a hydroponic nutrient solution that was developed by Hoagland and Arnon in year 1938 and revised by Arnon (1950) and is one of the most popular solution compositions for growing plants.

For selection of effective concentration, a constant number of seeds were germinated and grown under different concentration of salt ranging from $0.128 \mathrm{~g}$ to $0.896 \mathrm{~g}$. The seeds were germinate and grown well in control, $1 \mathrm{dS} / \mathrm{m}(0.128 \mathrm{~g}), 2 \mathrm{dS} / \mathrm{m}(0.256 \mathrm{~g})$ and $3 \mathrm{dS} / \mathrm{m}(0.384 \mathrm{~g})$. From $4 \mathrm{dS} / \mathrm{m}(0.512 \mathrm{~g})$ to $6 \mathrm{dS} / \mathrm{m}(0.768 \mathrm{~g})$ the seeds were germinated but growth is stunted. In $7 \mathrm{dS} / \mathrm{m}$ $(0.896 \mathrm{~g})$ the growth is very little.

For germination studies, Thermocol glasses $(200 \mathrm{ml})$ were surface sterilized with alcohol (Ethanol). A bangle stitched with 12 
net (surface sterilized) was placed below the mouth in every thermocol glass. The nutrient solutions were then added to the glasses according to their concentration mentioned on the glasses. Care should be taken that the nutrient solution must come above the net, it should remain in the level of net. The seeds were soaked for 24 hours seeds in water, then the seeds (10 per each glass) were placed on the top of the net fitted below the mouth of thermocol glasses. The glasses were then kept on the surface sterilized rack with proper light management at room temperature. 400 lux light is required for germination and growth of seeds. The glasses were being monitored regularly and if required respective concentration were added, the process is called Top-up. The readings were taken after 24 hours of germination. There were three replicates taken for each of control and treated concentrations solutions.

For morphological studies, the growth of the plant was evaluated by measuring the shoot length and root length of seedlings on $7^{\text {th }}$ day. Seed were allowed to germinate and leaf emergence was recorded. The seedlings were randomly picked from the sets of the control and treated plants. A $30 \mathrm{~cm}$ scale was used for measurement of shoot and root length. Another aspect of growth of the seedlings can be measured by comparing the fresh and dry weights (seedlings were dried in hot air oven) of the seedlings. The weights of the seedlings were measured in gram $(\mathrm{g})$ with the help of weighting machine.

The contents of various pigments (chlorophyll-a, chlorophyll-b, carotenoid and phaeophytin) of the seedlings were estimated and calculated following the formula of Arnon (1949) and expressed in $\mathrm{mg} / \mathrm{g}$ fresh weight. Biochemical analysis was made using the seven day old seedlings. The root and shoot portion of these seedlings were separated and weighted and analyzed for various biochemical components. The biochemical parameters for Root and Shoot of 7days old seedlings like Amino Acids (Moore and Stein,1948), Protein (Lowry et al., 1951), Carbohydrates/Sugar (Yoshida et al.,1972) and DNA and RNA (Schemider,1957) were estimated following standard quantitative methods.

\section{Results}

The results obtained during salt stress to mung seedlings were shown in the Plate No1 and Figure No.1-13.

Morphological Study:

During the experimental period the seed of Vigna radiata showed $100 \%$ germination in absence of salt stress (Control) ,however, when the salt stress was increased to the mung seeds, the germination percentage declined gradually(Fig.No.2).

The root and shoot length had the major impact of the seedling growth after salt treatment in comparison to controls (Plate No.1).The emergence of leaf also affected by salt stress (Fig .No. 3).

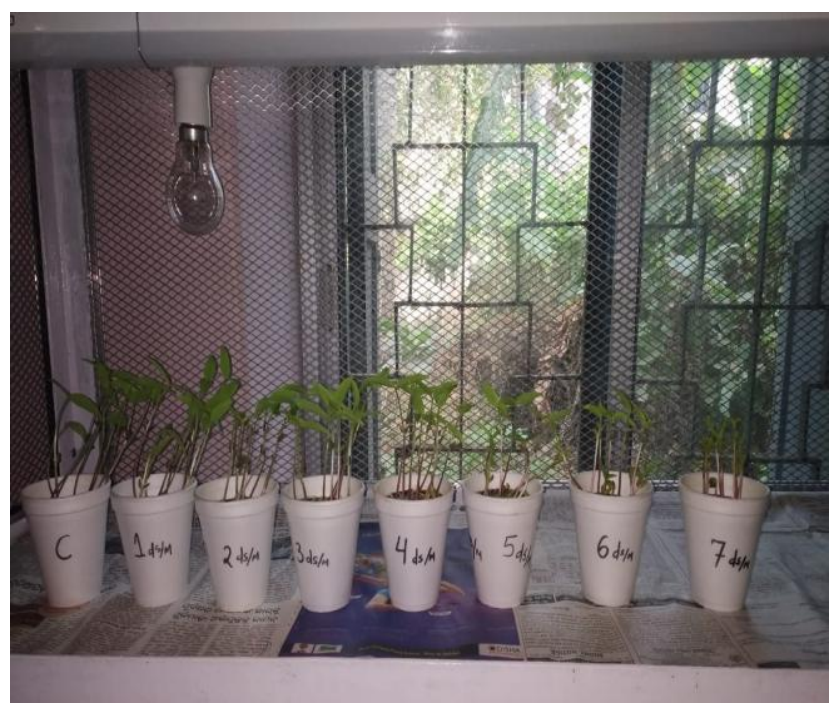

Fig. No.1 :Growth and Development of Mung Seedlings with salt stress for 7 days under laboratory conditions.

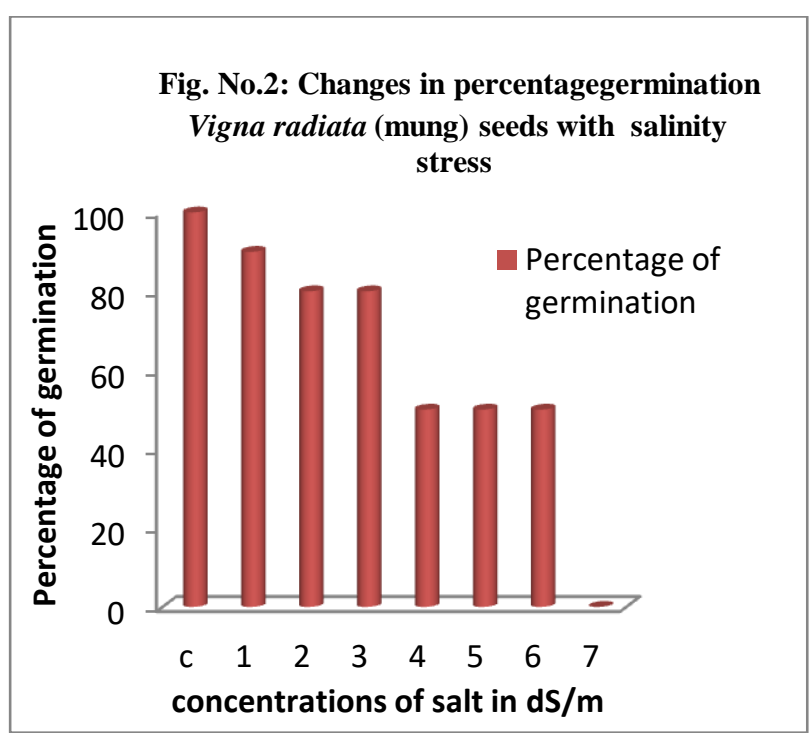

In shoot, there was a gradual decrease in the length as the concentration of salt increases.. In the 7th day the shoot length of control was $11.6 \mathrm{~cm}$ whereas, the length in $7 \mathrm{dS} / \mathrm{m}$ salt concentration is least i.e. $3.2 \mathrm{~cm}$. The root had same effect. The root length of control is $11.4 \mathrm{~cm}$ and in $7 \mathrm{dS} / \mathrm{m}$ concentration it's $6.2 \mathrm{~cm}$.

Beside root and shoot lengths, fresh and dry weights of seedlings can also be treated as the indices of growth. After seventh day salt treatment of the seedlings, the fresh weight of shoot and root were taken separately with the cut portions of shoots and roots. The fresh weight and Dry weight of the Shoot and Root of the 7thdays old seedlings showed a decline (Fig.No.5, 6) with the increase in Slat treatment to mung seedlings. 
Fig. No 3: Effect of salinity stress on Percentage of leaf emergence of Vigna radiata seedlings

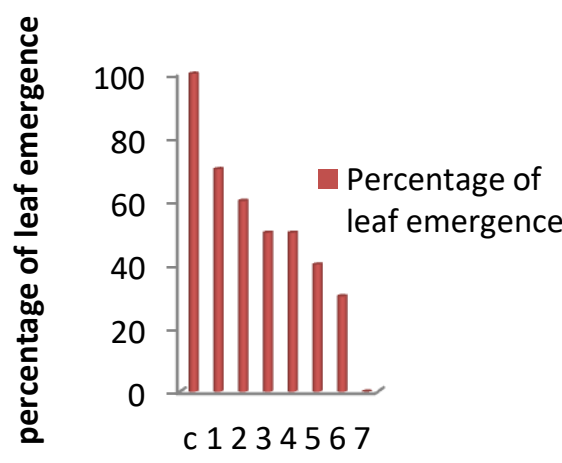

\section{Concentration of salt in $\mathrm{dS} / \mathrm{m}$}

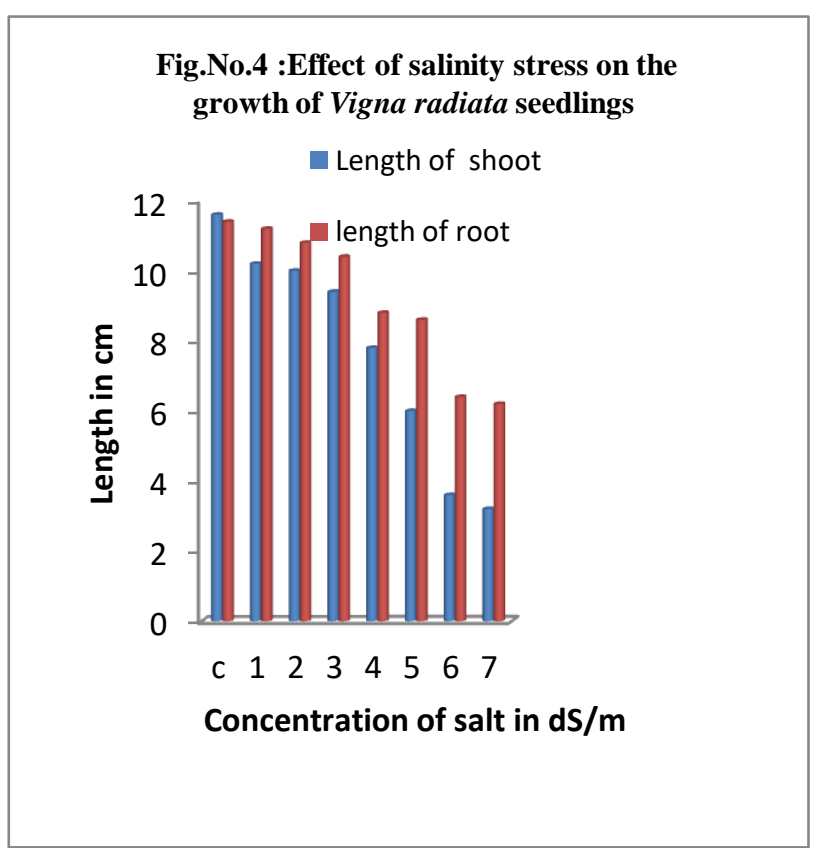

Plate No. 1 : Effect of salt stress on the Vigna radiata seedlings after 7 days treatment.

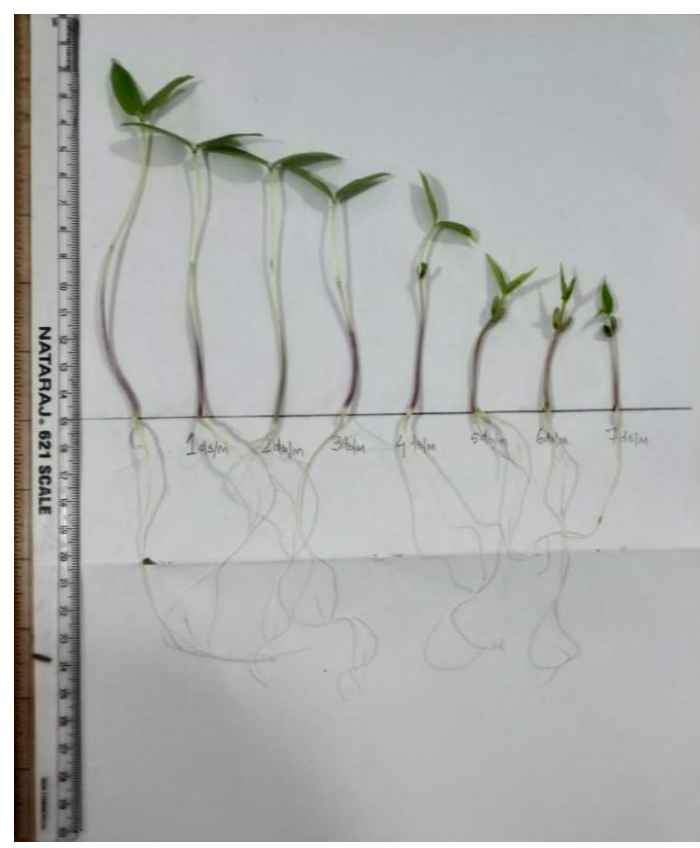

Fig. No.5 : Effect of Salinity Stress ondryweight/fresh weight of shoot of Vigna radiata seedlings

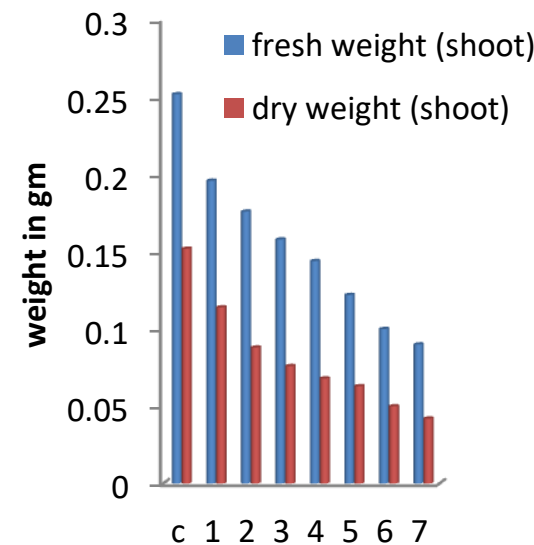

concentrations of salt in $\mathrm{dS} / \mathrm{m}$ 

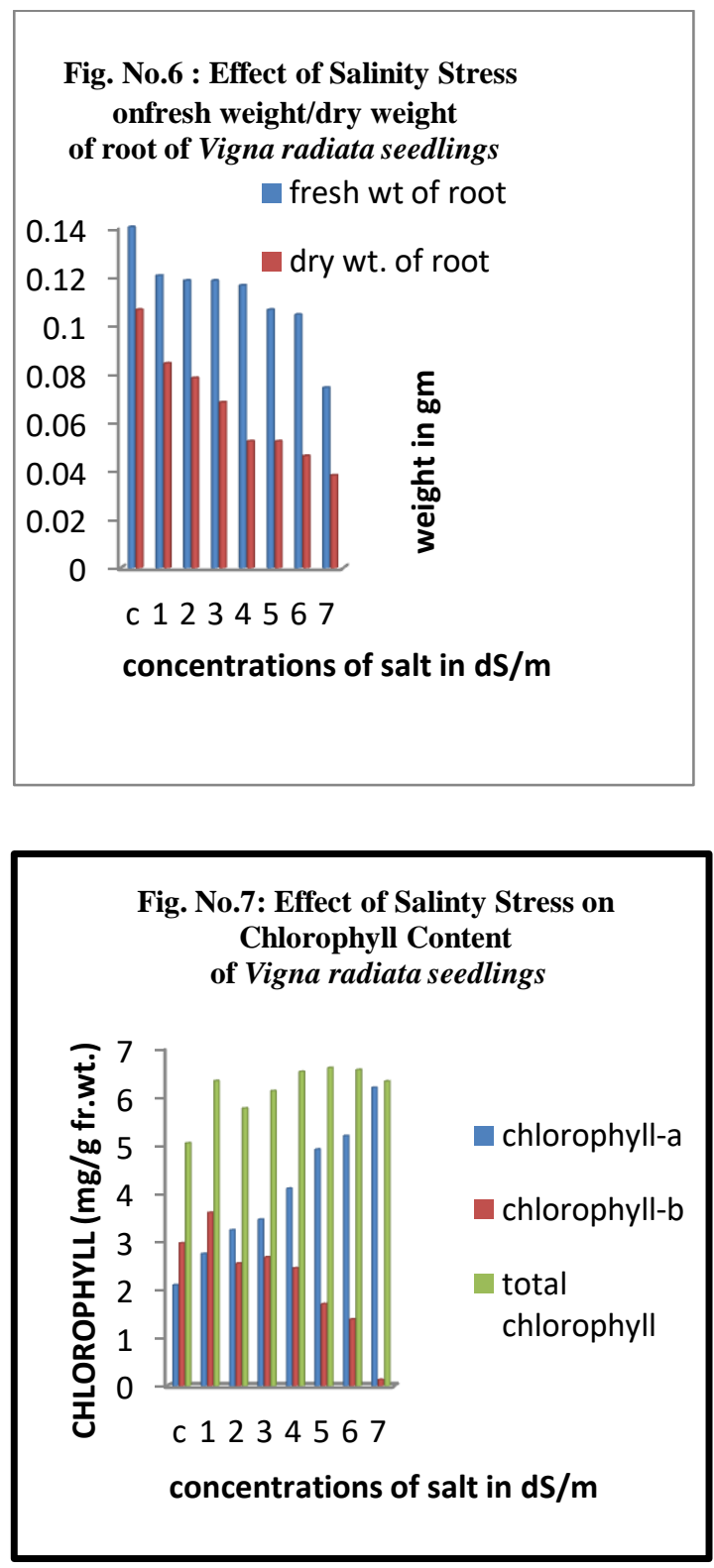

\section{Pigment Analysis :}

The estimation of chlorophyll was limited to the shoots only. The total chlorophyll contents were calculated taking different concentrations i.e. from $1 \mathrm{dS} / \mathrm{m}$ to $7 \mathrm{dS} / \mathrm{m}$ along with control solution and the results are presented in Fig. No.7-9.

The amount of chlorophyll-a increased with increase in concentration of salt . The amount of chlorophyll-a was $2.09 \mathrm{mg}$ in control seedlings, while $7 \mathrm{dS} / \mathrm{m}$ concentration have more chlorophyll $-\mathrm{a}$, i.e. $6.18 \mathrm{mg}$. However, the maximum content of total chlorophyll is found in $5 \mathrm{dS} / \mathrm{m}$ concentration i.e. $6.59 \mathrm{mg}$. The contents of total chlorophyll and chlorophyll-a of the seedlings increased with increase in salt concentration where as the contents of chlorophyll-b decreased (Fig.No.7). The amounts of carotenoid don't have a linear relation with various salt treatment. There was a sharp decrease in the carotinoid content from $1 \mathrm{dS} / \mathrm{m}$ salt stress. Again, at $5 \mathrm{dS} / \mathrm{m}$ concentration there was a sudden increase in the amount of carotenoid. After this increase there is a sharp decrease with the increase in salt stress.(Fig.No.8).

The amounts of phaeophytin don't respond with the salt stress. There is a sharp decrease in the contents of phaeophytin from $1 \mathrm{dS} / \mathrm{m}$ concentration and at $5 \mathrm{dS} / \mathrm{m}$ concentration there was a increase in the amount of phaeophytin followed by a decrease in carotenoid content. Hence, the salinity stress has almost similar effect on Phaeophytin as that of caroteniods (Fig. No.9).

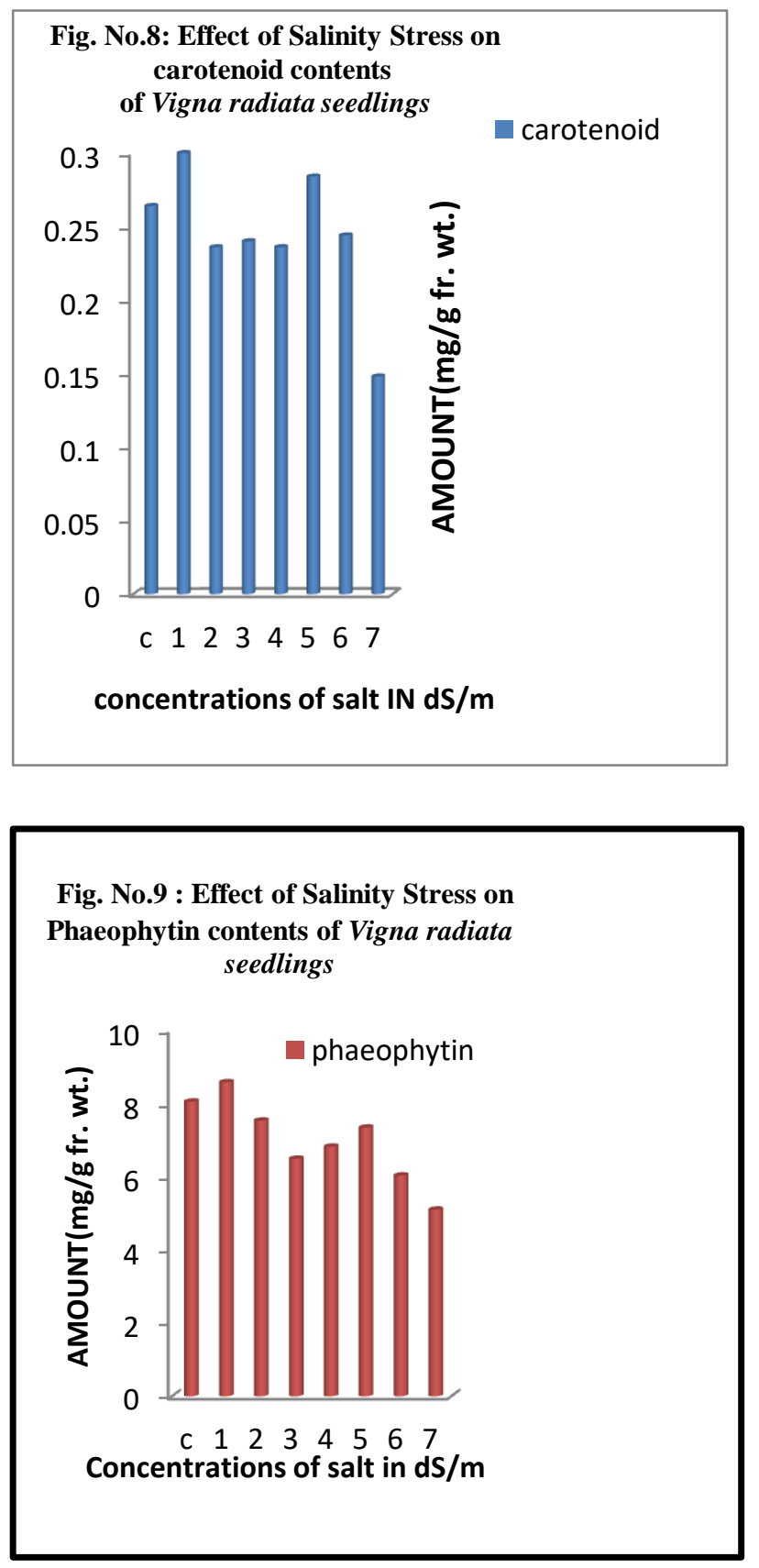




\section{Biochemical Analysis:}

The results of biochemical analysis is presented in Fig. No.10-13.

The contents of amino acid and sugar decreased with the increase in salt concentration (Fig. No.10) where as the protein contents show variations in root. The content of amino acid decreased with the increase in salt concentration in shoot of the seedlings while sugar and protein showed increase and decrease in their amount.

The amount of amino acid in shoot (Fig.No11) gradually decreased with the increase in concentration of salt. Similarly sugar content in shoots of the seedling showed a decrease with the increase in salt treatment., control has highest amount of sugar but there is two sudden increases in sugar content at concentration $3 \mathrm{dS} / \mathrm{m}$ and $6 \mathrm{dS} / \mathrm{m}$ concentrations. The protein content in shoots of the mung seedlings did not respond to the salt stress in regular increase or decreasing trend.

The DNA content in shoot of the seedlings (Fig. No.12) was found to be increasing at low salt stress but did not show a regular pattern of decline in DNA content. Same was the case in RNA contents of the seedlings.

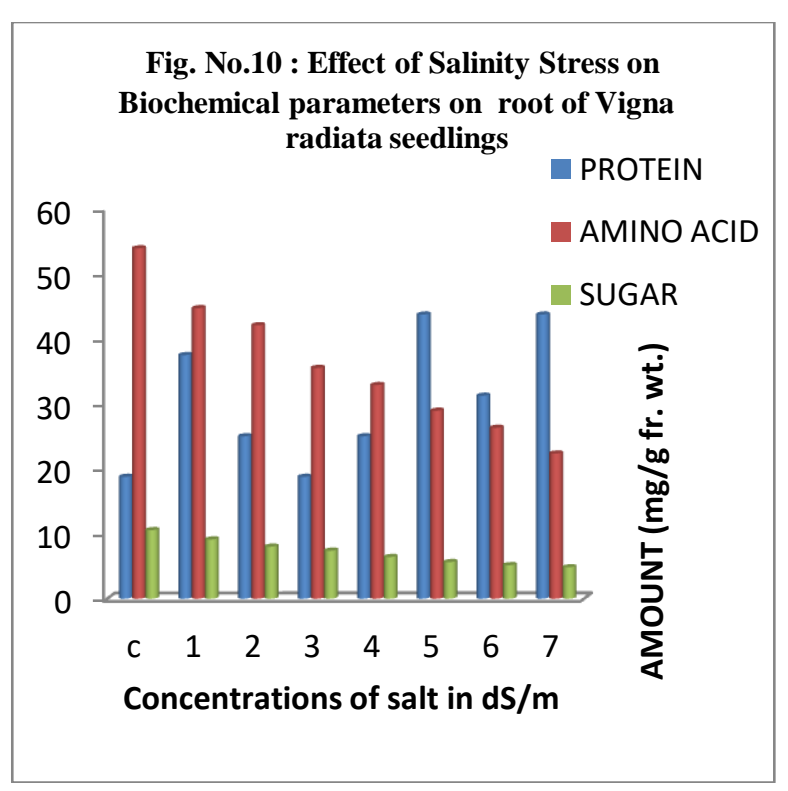

Fig. No. 11 : Effect of Salinity Stress on Biochemical parameters on shoot of Vigna radiata seedlings

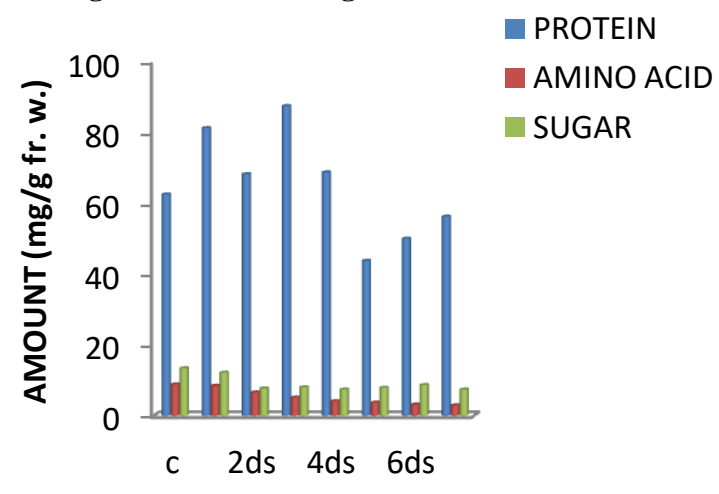

Concentrations of salt in $\mathrm{dS} / \mathrm{m}$

Fig. No.12 : Effcet of Salinity Stress on Nucleic acid contents of shoot of Vigna radiata seedlings

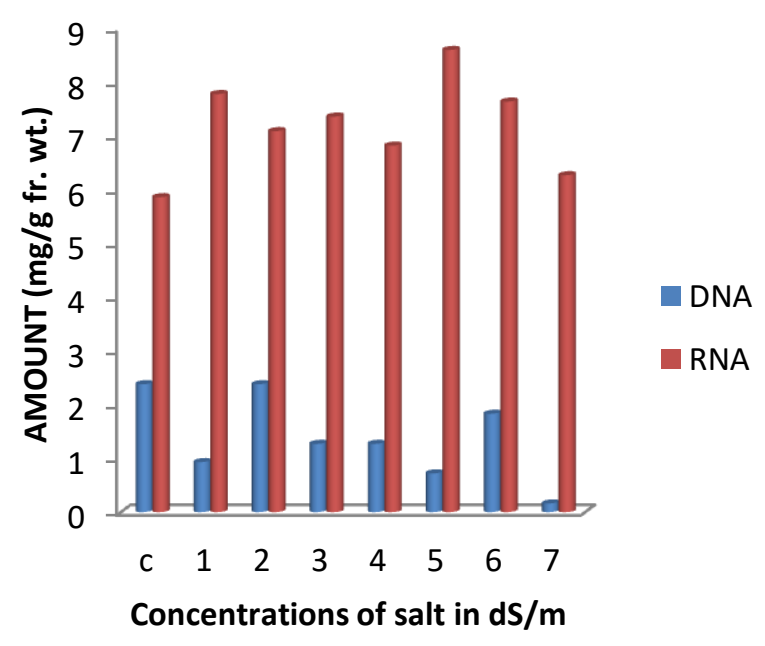




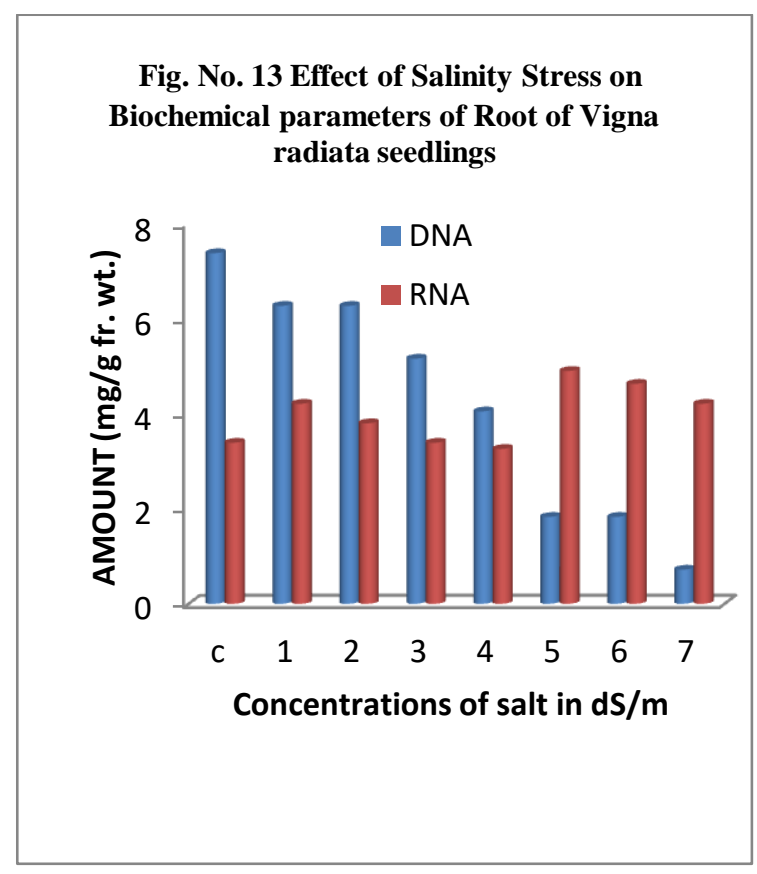

\section{Discussion}

In plants, the most critical stage during seedling growth is the seed germination and that determines effective crop establishment and production. Increasing salinity stress levels during mung bean seed germination significantly reduced the germination and seedling performance. Salinity adversely affects the plant growth at all stages, particularly at seedling stages, which dramatically reduces the percentage of germination and leaf emergence (Munns et al., 2002). Many earlier reports have shown that a significant reduction in shoot and root lengths in mung bean seedlings caused by salt stress was ameliorated by providing an induction treatment (with small dose of $\mathrm{NaCl}$ prior to exposure to the lethal concentration. The percent survival was relatively more and reduction in recovery growth was appreciable in pretreated plants over non treated plants, which indicates that pre-treatment has an assimilative effect in acclimation process as reported earlier in soybean and rice.

In our study, it was found that, the seeds were not pretreated and there was significant decrease in root length and shoot length, dry and fresh weight indicating even the sub-lethal dose is sensitive to the seedling. However, it was noticed that increasing in concentration of salt has stimulatory effect on chlorophyll-a but even the sublethal concentration shows high sensitivity to chlorophyll-b which resulted in little increase in total chlorophyll. Salinity has its own effects on the plant growth and development right from the germination stage. In the present study, all recorded parameters decreased in comparison to control plants. But in root, the protein content increased remarkably in sub-lethal concentration and decreased as the concentration was increased. The reduction of plant growth under salinity was due to the effect of salinity on the different vital activities of plants, such as declined enzymatic activity, metabolism, cell division and photosynthesis. Growth inhibition under salt stress may be due to the diversion of energy from growth to maintenance respiration. Increasing salinity concentration levels leads to an increase on the absorbance of some essential elements that activated the action of some enzymes, which were essential for the protein synthesis (Mayer. 1973). In the nucleic acid study, it was observed that, the salt stress had irregular effect on DNA and RNA contents. The result explains that germination and growth significantly decreased with higher salinity levels, no matter what the stress was, the plants put forth appreciable pod yield (Wahid.,2004).

Mung, by nature is susceptible to salinity and show wide and vivid response against the detrimental effects of increased salt accumulation. A preliminary study of the manifold works done to apprehend the effect of salinity and the response of the crop in turn has been illustrated here. With respect to the devastating effect of salinity on this staple food crop, it is very important assimilate the knowledge of the response of the crop towards salinity. This will aid in future work of improvement towards salinity tolerance and breeding for salinity tolerance. This work is a minor attempt to summarize the salient contributions and breakthroughs made in this area in the course of understanding the response and thus the plant defense to fight salinity as a stress.

From the results of the present investigation, it can be summarized, that the high salinity affects early growth of mung seedlings. Therefore, plants can acclimatize to sub-lethal level of salinity and can improve its production ability under saline conditions. Confirmatory field experiments of identified salinity tolerant lines have been planned to explore the field level tolerance.

\section{ACKNOWLEDGEMENT:}

The authors are thankful to the HOD, Botany and Principal of Khallikote Autonomous College, Berhampur, Odisha for encouragement of research activity and providing necessary laboratory facilities. The authors are also grateful to Dr. B .K. Mohanty, Visiting faulty for his timely guidance and help during preparation of this manuscript.

\section{REFERENCE:}

Ahmad, P. : Growth and antioxidant responses in mustard (Brassica juncea $L$.) plants subjected to combined effect of gibberellic acid and salinity. Arch . Agron. Soil Sci., 56(5):575-588, (2010).

Apel , K. and Hirt , H.: Reactive oxygen species: metabolism, oxidative stress, and signal transduction. Annu . Rev. Plant Physiol . 55: 373-399, (2004)

Arnon D.I: Copper enzymes in isolated chloroplasts polyphenol oxidase in Beta vulgaris. Plant Physiol. 24:1$15,(1949)$

Arnon D.J : Chlorophyll absorption spectrum and quantitative determination. Bioch.Bioph.Acta 20: 449-461, (1950) 
Grewal, H.S. : Water uptake, water use efficiency, plant growth and ionic balance of wheat, barley, canola and chickpea plants on a sodic vertosol with variable subsoil $\mathrm{NaCl}$ salinity. Agric. Water Manag. 97, 148-156,(2010)

Hesegawa,P.M., Bressan R.A., Zhu, J.K., Eohnert H.J: Plant cellular and molecular response to high salinity. Anna. Rev. Plant phys, S1. 403-499, (2000)

Lowry OH, Rosen-brought NJ, Farr AL and Randal RJ: Protein Measurement with the Folin Phenol reagent. $J$. Biol. Chem.;193; 265-275,(1951):

Mayer BS, Anderson DB, Bohning RH, Fratianne DG: Introduction to plant physiology. D. Van no strand company, New York. U.S.A (1973)

Moore S and Stein WW: Photometric ninhydrin method for use in the chromatography of amino acids, J. Biol. Chem.,176, 367-388,(1948)

Munns R, Husain S, Rivelli AR, James RA, Condon AG, Lindsay MP, Lagudah ES, Schachtman DP, Hare R A : Avenues for increasing salt tolerance of crops, and the role of physiologically based selection traits. Plant and Soil, 247: 93-105,(2002)

Saha $\mathrm{P}$, Chatterjee $\mathrm{P}$, Biswas $\mathrm{AK}: \mathrm{NaCl}$ pretreatment alleviates salt stress by enhancement of antioxidant defense and osmolyte accumulation in rice bean Vigna radiata(L.) Wilczek., Indian J. Exp. Biol., 48593-48600, (2010)
Schmeider WC : Determination of nucleic acids of tissues by pentose analysis. In: Methods Enzymnology- Vol.3. (S.O. Colowick and N. O. Kplan. Eds) 680-684, Academic Press, New York, (1957):

Singh,M., Kumar,J., Singh,V.P., and Prasad,S.M : Plant tolerance mechanism against salt stress: the nutrient management approach. Biochem. Pharmacol. 3(5),:e165.(2014) :

Vaidyanathan, H., Sivakumar, P., Chakrabarty, R., Thomas, G., : Scavenging of reactive oxygen species in $\mathrm{NaCl}$-stressed rice (Oryza sativa $\mathrm{L}$.): differential response in high yielding and sensitive varieties. Plant Science 165, 1411-1418,(2003)

Van Breusegem, F., Dat, J.F : Reactive oxygen species in plant cell death. Plant Physiology ,141 , 384-390,(2006)

Verma, S., Mishra, S.N: Putrescine alleviation of growth in salt stressed Brassica juncea by inducing antioxidative defense system. Journal of Plant Physiology 162, 669677,(2005)

Wahid A and Ejaz MHR : Salt injury symptom, changes in nutrient and pigment composition and yield characteristics of rice-bean. Int. J. Agric .Biol. 6, 1143-1152,(2004)

Yoshida S, Forno DA, Cock JH and Gomez KA (1972): Laboratory manual for physiological studies on rice- Int. Rice Res. Inst. Los Banes, Philippines, 1972 